PAPER

\title{
Perception of Japanese consonant-vowel syllables in reverberation: Comparing non-native listeners with native listeners*
}

\author{
Eri Osawa ${ }^{1, \dagger}$, Takayuki Arai ${ }^{1, \ddagger}$ and Nao Hodoshima ${ }^{2}$ \\ ${ }^{1}$ Sophia University, \\ 7-1 Kioi-cho, Chiyoda-ku, Tokyo, 102-8554 Japan \\ ${ }^{2}$ Tokai University, \\ 2-3-23 Takanawa, Minato-ku, Tokyo, 108-8619 Japan
}

(Received 30 November 2017, Accepted for publication 25 June 2018)

\begin{abstract}
Long reverberation degrades the intelligibility of speech sounds. Previous studies have reported that non-native listeners have difficulty in understanding speech in reverberation more than native listeners. In the results of the previous studies, there was the possibility that lower identification scores for non-native listeners were attributed to non-native phonemes which did not exist in their native languages. The current study investigated the identification of Japanese consonant-vowel (CV) syllables in reverberation for native English listeners whose native language has counterparts to most or all Japanese consonants. The current study used $62 \mathrm{CV}$ syllables as stimuli. The reverberation time of the reverberant condition was $2.7 \mathrm{~s}$. The results showed that the correct answer rate for non-native listeners declined in the reverberant condition more than that for native listeners. There was significant difference between native and non-native listeners in the correct answer rate of $/ \mathrm{m}, \mathrm{r}, \mathrm{k}, \mathrm{d}, \mathrm{s} / \mathrm{in}$ reverberation. The results suggested that non-native listeners had disadvantage in listening to nonnative consonants even if their native languages had counterparts to the consonants. In addition, the results suggested that native English listeners might had advantage in finding acoustic cues of place of articulation in adverse environments because of the inventory of English.
\end{abstract}

Keywords: Speech perception, Reverberation, CV syllable, Japanese

PACS number: 43.71.Hw, 43.66.Dc, 43.55.Hy [doi:10.1250/ast.39.369]

\section{INTORODUCTION}

\subsection{The Effects of Reverberation on Speech Intelligi- bility}

Since long reverberation reduces speech intelligibility, listeners often have difficulty in understanding speech in reverberant environments. The degradation is attributed to overlap-masking and self-masking [4,5]. The energy of a preceding phone overlaps the following phone because of the energy to which reverberation adds (overlap-masking), and temporal energy within each speech sound is smeared (self-masking) in reverberation.

Previous studies [6-8] have shown that non-native listeners had difficulty in identifying phonemes and misheard phonemes more than native listeners in the reverberant condition even though the performance difference

${ }^{*}$ The current paper includes the results for native listeners in Arai $[1,2]$. The parts of the results for non-native listeners in the current paper were preliminarily published [3].

†e-mail: eri1989.16.11@gmail.com

†e-mail: arai@sophia.ac.jp was small between native and non-native listeners in the non-reverberant condition. Nábělek and Donahue [6] showed non-native English listeners who spoke English fluently performed poorer in English consonants identification in the reverberant condition using the Modified Rhyme Test (MRT). Stimuli were recorded with reverberation time (RT) of $0.4,0.8$, and $1.2 \mathrm{~s}$ which were supposed to be typical places in real life environments. The score for non-native listeners was lower than that for native listeners in all of three reverberant conditions. It indicated that nonnative listeners have difficulty in identifying phonemes even in moderate reverberation. In addition, the study [6] suggested that the phoneme system in native languages of non-native listeners affected the error patterns in reverberation. The results showed that Asian listeners (Japanese and Chinese) confused English liquid with glide consonants more frequently than Polish listeners.

Takata and Nábělek [7] examined English consonant identification in reverberation by native Japanese listeners who were fluent in English, using MRT. The study also showed that the correct answer rate for non-native listeners 
declined more than that for native listeners in the reverberant condition even though the correct answer rates for both listeners were close to $100 \%$ in the quiet condition. According to non-native listeners' error patterns, Japanese listeners tended to frequently confuse English /r/ with /1/ in the reverberant condition. Both previous studies [6,7] suggested that non-native listeners (Japanese listeners) have difficulty in the perception of phonemes which do not exist in their native language (Japanese) in the reverberant condition.

Masuda [8] also examined 23 English consonant intelligibility in the various reverberant conditions for native English listeners and native Japanese listeners. Although the results confirmed main effect of listening condition on the overall identification rates, there was no main effect of language group. The interaction was not significant. However, the results confirmed main effect of language group on the identification rate of a subset of consonants /f, $\mathrm{d}, 3, \mathrm{l}, \mathrm{I}, \mathrm{s}, \mathrm{\int}, \theta$, , $, \mathrm{v}, \mathrm{z} / \mathrm{which}$ were supposed that Japanese listeners often had difficulty in identifying. The results of the subset of consonants also indicated that native Japanese listeners might have disadvantage in identifying English consonants which Japanese did not have the counterparts to in reverberation.

The previous studies [6-8] showed that non-native listeners had difficulty in identifying English consonants which did not exist in their native languages. Therefore, the lower identification rate for non-native listeners might be attributed to the identification rates of the consonants which their native languages did not have. There is the possibility that non-native listeners do not have disadvantage in identifying non-native consonants which their native languages have counterparts to even in reverberation.

\subsection{The Perception of Second Language Sounds}

The perception of non-native phonemes which do not exist in the native language of a listener have investigated in the second language (L2) learning research. The theoretical models for non-native speech perception have been introduced, such as the Perceptual Assimilation Model for L2 learners (PAM-L2) by Best and Tyler [9], the Native Language Magnet (NLM) model by Kuhl and Iverson [10], and the Speech Learning Model (SLM) by Flege [11]. The three models argue that native language of a listener often make the L2 speech perception difficult since the categories and the prototypes of categories of native language are often used for the L2 perception. Kuhl expressed that categories of native language are like a filter which a listener perceive the L2 sounds through [10].

The results of Masuda [8] corresponded with the claim of PAM-L2. An assimilation type in PAM-L2 predicts that listeners assimilate two non-native speech sounds into one category which exist in their native languages (Single-
Category assimilation). In Single-Category assimilation, the discrimination between the non-native two sounds is expected to be difficult for non-native listeners. On the other hand, if non-native listeners could perceive a nonnative phone as equivalent to a given phonological category of their native languages (Two-Category assimilation), they do not need further training for acquiring the sound [9].

\subsection{The Aim of the Present Paper}

Although the previous studies [6-8] indicated that non-native listeners had difficulty in understanding speech sounds in reverberation, it has not been revealed that the results could be generalized to when other languages are used as the target language because they all used English as the target language. It was needed to investigate whether non-native listeners had difficulty in understanding speech sounds in reverberation if native language of non-native listeners had counterparts to all consonants of the target language. We could infer from the results of Masuda [8] that there would be little difference between native and non-native listeners in identifying consonants in reverberation.

The current study examined the identification of Japanese phonemes by native English listeners in reverberation. Japanese has less consonants than English does, and Japanese consonants could be regarded as a subset of English consonants. Although Japanese has consonants which English does not have as a phoneme, English has counterparts to most or all Japanese consonants including sounds across morpheme boundaries. Therefore, we inferred that native English listeners would identify Japanese consonants as well as native Japanese in reverberation.

The current study used consonant-vowel (CV) syllables as the target. The previous studies on the intelligibility of Japanese for native Japanese listeners in reverberation $[1,2,12]$ used CV syllables for examined the intelligibility of consonants. Hodoshima [12] examined the Japanese $\mathrm{CV}$ syllable intelligibility in various reverberant conditions, and reported that perceptual errors increased when the reverberation time became longer. Arai et al. [1,2] investigated intelligibility of Japanese CV syllables in reverberation $(\mathrm{RT}=2.7 \mathrm{~s})$ conducting the experiment which expanded the previous study [12]. Arai et al. [1,2] revealed that native Japanese listeners tended to confuse fricative and nasal consonants with stop consonants in the reverberant condition, and they hardly misheard voiceless consonants as voiced consonants. Arai et al. [1,2] did not report about place errors and the total number of each error type. The current study classified errors into voicing, manner, and place errors, and compared the results for nonnative listeners with those for native listeners. 
Table 1 Combination patterns of 18 consonants and five vowels.

\begin{tabular}{cc}
\hline Consonant & Following vowel \\
\hline$/ \mathrm{p} /, / \mathrm{k} /, / \mathrm{b} /, / \mathrm{g} /$ & $/ \mathrm{a} /, / \mathrm{i} /, / \mathrm{u} /, / \mathrm{e} /, / \mathrm{o} /$ \\
$/ \mathrm{t} /, / \mathrm{d} /$ & $/ \mathrm{a} /, / \mathrm{e} /, / \mathrm{o} /$ \\
$/ \mathrm{s} /, / \mathrm{dz} /$ & $/ \mathrm{a} /, / \mathrm{u} /, / \mathrm{e} /, / \mathrm{o} /$ \\
$/ 6 /$ & $/ \mathrm{i} /$ \\
$/ \mathrm{h} /$ & $/ \mathrm{a} /, / \mathrm{i} /, / \mathrm{u} /, / \mathrm{e} /, / \mathrm{o} /$ \\
$/ \mathrm{t} 6 /, / \mathrm{d} /$ & $/ \mathrm{i} /$ \\
$/ \mathrm{ts} /$ & $/ \mathrm{u} /$ \\
$/ \mathrm{m} /, / \mathrm{n} /$ & $/ \mathrm{a} /, / \mathrm{i} /, / \mathrm{u} /, / \mathrm{e} /, / \mathrm{o} /$ \\
$/ \mathrm{r} /$ & $/ \mathrm{a} /, / \mathrm{i} /, / \mathrm{u} /, / \mathrm{e} / / \mathrm{o} /$ \\
$/ \mathrm{j} /$ & $/ \mathrm{a} /, / \mathrm{u} /, / \mathrm{o} /$ \\
$/ \mathrm{w} /$ & $/ \mathrm{a} /$ \\
\hline
\end{tabular}

\section{EXPERIMENT}

\subsection{Stimuli}

$62 \mathrm{CV}$ syllables were made from 18 consonants and five vowels. Table 1 shows the combination patterns of consonants and vowels. In the current paper, /6/ was regarded as a phoneme whereas $[c ̧]$ and $[\phi]$ were regarded as allophones of $/ \mathrm{h} /$, and $[\mathrm{n}]$ was regarded as an allophone of $/ \mathrm{n} /$ (based on [13]). In addition, Japanese [dz] and [z] are considered allophones which are free variant. In this paper, /dz/ is used as representation which includes [z] as an allophone because the target consonant was uttered as a consonant in the syllable-initial position. All syllables were phonologically eligible.

All CV syllables were presented to the participants embedded in the Japanese carrier sentence, "Korekara kikoete kurunowa ___ desu" (You will hear __..). There was a $150 \mathrm{~ms}$ gap of silence before the target CV syllable, and $50 \mathrm{~ms}$ after the target. Although all CV syllables were spoken in a carrier sentence when they were recorded, the $\mathrm{CV}$ syllables were extracted from a carrier sentence. We selected a carrier sentence which all CV syllables were embedded in for standardizing the overlap-masking effect on each syllable. We selected the carrier sentence which was pronounced clearly, and whose fluctuation in intensity was small. The CV syllables embedded in the selected carrier sentence were used as stimuli. Since the fluctuation among CV syllables in intensity was small, the original intensity of the tokens were used as stimuli. The duration of the carrier phrase preceding the target CV syllables was $1,563.1 \mathrm{~ms}$, and the duration of the carrier phrase following the target was $496 \mathrm{~ms}$. The average duration of CV syllables was $204.6 \mathrm{~ms}(\mathrm{SD}=42.1 \mathrm{~ms})$.

An adult male speaker of Tokyo standard Japanese pronounced the tokens. He was in his early 20's. He pronounced all $\mathrm{CV}$ syllables in the carrier sentence. The recording was conducted in a sound-proof room. The tokens were digitally recorded at a sampling rate of
$44.1 \mathrm{kHz}$ (16 bits) with a linear PCM recorder (Sony PCMD50) and a microphone (Sony ECM-MC957).

\subsection{Participants}

Two groups participated in the experiment. The nonnative listener group consisted of ten native English listeners whose mean age was 22.8 years $(\mathrm{SD}=2.3$ years). Three were male and seven were female. There were eight Americans, one British, and one Australian. Their mean age of arrival in Japan was 22.2 years $(\mathrm{SD}=$ 2.4 years). They were all students who learned Japanese at universities in Japan. In the current study, non-native listeners whose length of residence in Japan (LOR) was similar to each other were recruited for the experiment. It is often a problem for learners that non-native speech sounds in real life environments differ from those they listen to in a classroom. Masuda [8] regarded LOR as an index of amount of language experience which helps listening non-native sounds in adverse listening environments. Their mean LOR in Japan was 7.2 months $(\mathrm{SD}=3.2$ months, range $=2-11$ months). Since none of the non-native participants had took Japanese-Language Proficiency Test, we referred to the length of learning Japanese (LOLJ). LOLJ included both length of learning by themselves and in school, and also included length of both learning in Japan and in their own countries. The mean LOLJ was 3.5 years $(\mathrm{SD}=3$ years, range $=9$ months to 10 years).

The native group, as control group, consisted of eleven native Japanese listeners whose mean age was 23.5 years $(\mathrm{SD}=3.1$ years). Three were male and eight were female.

No participant reported any hearing or speaking disorder.

\subsection{Experiment Conditions}

The experiment was conducted in a sound-proof room in a laboratory at Sophia University, and the experiments of both the reverberant and non-reverberant conditions were conducted there. All stimuli were stored in the PC $\left(\right.$ Intel ${ }^{\circledR}$ Core $^{\mathrm{TM}} 2$ Quad CPU, $2.83 \mathrm{GHz}$ ), and they were presented via an audio interface (RME Fireface 800) and a digital mixer (Yamaha DME24N). The current study used a digital reverberator (Roland RSS-303) for adding reverberation to the stimuli. We selected a reverberant situation from the programs of the reverberator referring to the RT of an airport where both native and non-native listeners often have difficulty in understanding announcements. According to Yokoyama et al. [14], the RT of a lobby of Haneda airport was about $2.5 \mathrm{~s}$ at $500 \mathrm{~Hz}$. Therefore, the current study used a reverberant condition where RT was $2.7 \mathrm{~s}$ which was the closest to the RT of a lobby of Haneda airport.

The RT of the experiment was measured using swept sine signal. The swept sine signal was played through 
loudspeakers which were used in the experiments (Genelec 8020A), and RT was measured via a precision sound-level meter (RION NA-27). RT was measured at the listeners' head position. RTs of the two conditions were derived from the RTs average at $0.5,1$, and $2 \mathrm{kHz}$. The RT of nonreverberant condition which was carried out by bypassing the reverberator (Roland RSS-303) was also measured using the same method. The RT of the non-reverberant condition was $0.1 \mathrm{~s}$.

Stimuli with reverberation were presented from four loudspeakers (Genelec 8020A) surrounding a participant in the reverberant condition. The loudspeakers were along a circle with a radius of $1.3 \mathrm{~m}$ at equal angles of 45 degrees for left/right and front/rear. The loudspeaker height was $1.2 \mathrm{~m}$. The current study used the four loudspeakers surrounding a participant for simulating reverberant environments where sounds came from various directions. On the other hand, two loudspeakers in front of a participant were used in the non-reverberant condition for simulating the situation that a listener perceived just a direct sound from a talker. Since the same stimulus was presented from each of the two loudspeakers in the front, the participants perceived the stimulus from the center of the two loudspeakers.

\subsection{Procedure}

The perceptual experiment was conducted in a soundproof room where the background noise level was 20.2 A-weighted dB. Using Praat [15], the participants were asked to choose a correct answer from 62 choices regarding the speech sound they heard. The $62 \mathrm{CV}$ syllables in Roman letters were in the traditional fiftysound display of hiragana which is familiar to native Japanese listeners and learners of Japanese (Fig. 1). The participants gave their responses by pressing a button of the CV which they thought they heard. After a participant gave a response, OK button appeared on the PC screen. Pressing the OK button started the next stimulus. The sound level was adjusted for each participant using the carrier sentence preceding the target, and it was not

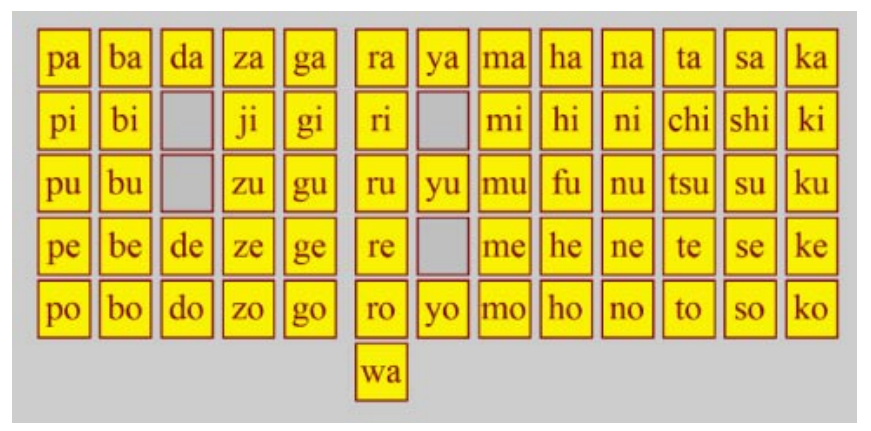

Fig. 1 Experiment interface. changed throughout the experiment. It was between 60-65 A-weighted dB. Each stimulus was presented to participants three times in random order. The experiment in the reverberant condition was carried out first, and followed the non-reverberant condition. Thus a total of 372 trials (62 syllables $\times 3$ repetitions $\times 2$ reverberant conditions) were conducted for each participant. The researcher explained and showed how to give responses to participants, and they practiced proceeding the experiment prior to the test session to familiarize themselves with the procedure. They just tried the procedure without sounds. It took about five min.

\section{RESULTS}

\subsection{Overall Results}

Figure 2 shows the mean correct answer rates for native listeners (NL) and non-native listeners (NNL). Bars in left shows the results in the non-reverberant condition, and bars in right shows the results of the reverberant condition. The mean correct answer rate in the nonreverberant condition for native listeners was $98.0 \%$ ( $\mathrm{SD}=$ $1.9 \%$ ). It declined to $84.7 \%$ ( $\mathrm{SD}=3.4 \%$ ) in the reverberant condition. The mean correct answer rate in the nonreverberant condition for non-native listeners was $95.6 \%$ $(\mathrm{SD}=1.4 \%)$. It declined to $76.7 \%(\mathrm{SD}=5.7 \%)$ in the reverberant condition. $2 \times 2$ ANOVA for repeated measures was performed on the correct answer rate. The results confirmed the interaction effect to be statistically significant $(F(1,19)=8.051, p=0.0105)$. Analysis of simple main effect revealed that the correct answer rate in the reverberant condition was significantly different from that in the non-reverberant condition for both native listeners $(F(1,20)=127.6, p<0.001)$ and non-native listeners $(F(1,18)=103.7, p<0.001)$. In addition, the correct answer rate for native listeners was significantly different from that for non-native listeners both in the non-

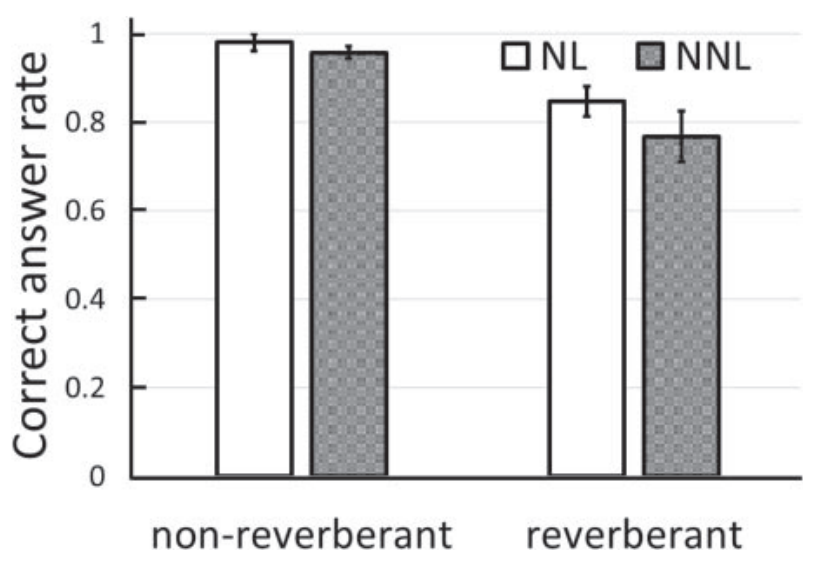

Fig. 2 The correct answer rate for native listeners (NL) and non-native listeners (NNL) in the non-reverberant condition (left) and the reverberant condition (right). 
reverberant condition $(F(1,19)=10.06, p<0.001)$ and the reverberant condition $(F(1,19)=15.53, p<0.001)$.

\subsection{The Correct Answer Rates of Each Consonant for Each Listener Group}

For investigating the differences in the effect of reverberation among consonants, the correct answer rates of each consonant were calculated (see Appendix 1-4). According to the test of proportion, the correct answer rates of $/ \mathrm{d} /, / \mathrm{s} /, / \mathrm{t}_{\mathrm{c}} /, / \mathrm{ts} /, / \mathrm{j} /$ were $100 \%$ for native listeners in the reverberant condition whereas the correct answer rates of all consonants for non-native listeners did not reach $100 \%$ in the reverberant condition.

The current study used the test of the difference between two proportions for revealing the difference between the reverberant conditions. The results revealed that the correct answer rates of /p, b, t, g, d, h, m, n, r/ in the reverberant condition were significantly lower than those in the non-reverberant condition $(p<0.01)$ in the results for native listeners. The results for non-native listeners also showed that the correct answer rates of $/ p, b$, $\mathrm{t}, \mathrm{g}, \mathrm{d}, \mathrm{h}, \mathrm{m}, \mathrm{n}, \mathrm{r} /$ declined in the reverberant condition significantly $(p<0.01)$. Of those consonants, the test of the difference between two proportions revealed that the correct answer rates of $/ \mathrm{m}, \mathrm{r} /$ for non-native were significantly lower than those for native listeners in the reverberant condition $(p<0.01)$. Although the results also indicated that there was a significant different between listener groups in the correct answer rate of $/ \mathrm{n} /$ in the reverberant condition, the correct answer rate of $/ \mathrm{n} /$ for non-native listeners was lower than that for native listeners in the non-reverberant condition $(p<0.001)$.

In addition, the test of the difference between two proportions revealed that the correct answer rates of $/ \mathrm{k}$, $\mathrm{d}, \mathrm{s} /$ for non-native listeners were significantly lower than those for native listeners in the reverberant condition $(p<0.01)$. The rates of $/ \mathrm{k}, \mathrm{d}, \mathrm{s} /$ for native listeners did not differ between conditions at all whereas those for nonnative listeners declined in the reverberant condition.

\subsection{Types of Confusions}

For revealing the difference between the reverberant conditions in confusion patterns for each listener group, the test of the difference between two proportions was used. Table 2 shows consonants which were misheard in the reverberant condition more than in the non-reverberant condition significantly $(p<0.01)$. The left column shows the results for native listeners, and the right column shows that for non-native listeners. In Table 2, the consonants in the column labeled "Stimuli" indicates the consonants which participants listened to in the experiment. The consonants in the column labeled "Response" indicates the consonants which participants confused the stimuli with.
Table 2 The consonants which were misheard in the reverberant condition more than in the non-reverberant condition for native and non-native listeners.

\begin{tabular}{cc|cc}
\hline \multicolumn{2}{c|}{ Native listeners } & \multicolumn{2}{c}{ Non-native listeners } \\
\hline Stimuli & Response & Stimuli & Response \\
\hline $\mathrm{p}$ & $\mathrm{k}, \mathrm{h}$ & $\mathrm{p}$ & $\mathrm{h}$ \\
$\mathrm{b}$ & $\mathrm{p}, \mathrm{g}$ & $\mathrm{b}$ & $\mathrm{p}$ \\
$\mathrm{t}$ & $\mathrm{p}, \mathrm{k}$ & $\mathrm{t}$ & $\mathrm{p}, \mathrm{k}$ \\
$\mathrm{g}$ & $\mathrm{k}$ & $\mathrm{d}$ & $\mathrm{t}$ \\
$\mathrm{d}$ & $\mathrm{t}$ & $\mathrm{h}$ & $\mathrm{p}$ \\
$\mathrm{h}$ & $\mathrm{p}$ & $\mathrm{m}$ & $\mathrm{b}$ \\
$\mathrm{m}$ & $\mathrm{b}$ & $\mathrm{n}$ & $\mathrm{b}, \mathrm{m}, \mathrm{r}$ \\
$\mathrm{n}$ & $\mathrm{m}, \mathrm{r}$ & $\mathrm{r}$ & $\mathrm{b}$ \\
$\mathrm{r}$ & $\mathrm{b}$ & & \\
\hline
\end{tabular}

In addition, the difference between listener groups in the confusion patterns in each reverberant condition was investigated. According to the results, non-native listeners misheard /d/ as /r/, /k/ as /p/, /s/ as /ts/, and /n/ as /r/ more than native listeners in reverberation significantly $(p<0.01)$. There was no confusion which native listeners made more than non-native listeners significantly in reverberation.

In the current paper, we classified errors into three types: voicing, place of articulation, and manner of articulation. For example, /p/-/b/ confusion was classified as a voicing error, $/ \mathrm{k} /-/ \mathrm{p} /$ confusion as a place error, and $/ \mathrm{d} /-/ \mathrm{r} /$ confusion as a manner error. When a confusion included more than two types of error, the confusion was counted in each of the types. For example, /n/-/b/ confusion was classified as a place error, and also counted as a manner error. Figure 3 shows the total number of each error type.

The three-way ANOVA for repeated measures was performed on the number of errors. The results confirmed the secondary interaction effect to be statistically significant (native language of listeners $\times$ reverberant conditions $\times$ types of errors $)(F(2,38)=4.235, p<0.05)$. Analysis of simple interaction found that the interaction between the native languages of listeners and the reverberant conditions in the number of manner errors was significant $(F(1,57)=14.989, p<0.001)$. In addition, the interactions between native languages and error types in the reverberant condition was significant $(F(2,76)=$ $11.66, p<0.001)$, and the interaction between the reverberant conditions and error types was significant in the result of both native listeners $(F(2,38)=14.821, p<$ $0.001)$ and non-native listeners $(F(2,38)=25.9, \quad p<$ $0.001)$. Subsequent analysis of simple main effect revealed that non-native listeners made manner errors more than native listeners in the reverberant condition $(F(1,114)=$ 43.346, $p<0.0001)$. There were not significant differences in the number of voicing errors and place errors 


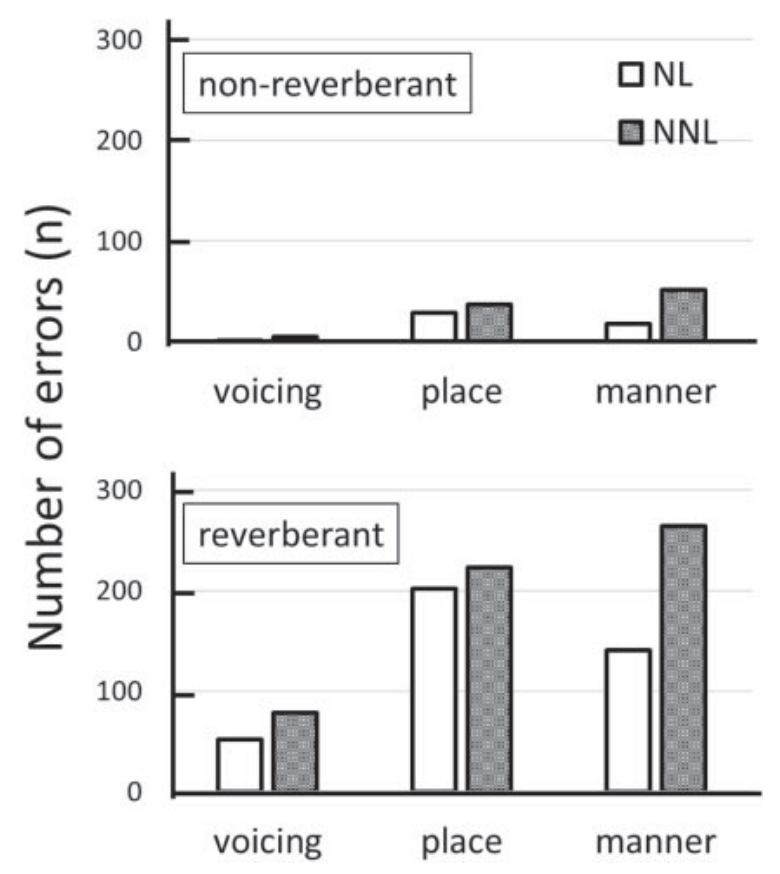

Fig. 3 The total number of voicing errors, place errors, and manner errors for native listeners (NL) and nonnative listeners (NNL) in the non-reverberant (top) and reverberant conditions (bottom).

between native and non-native listeners in the reverberant condition.

\subsection{The Correct Answer Rates of Each Vowel}

Tables 3 and 4 show the correct answer rates of each vowel. The test of the differences between two proportions revealed that there was significant difference in the correct answer rates of /i/ for native listeners between the reverberant and non-reverberant condition $(p<0.05)$. There were no significant differences in the correct answer rates of the other vowels for native listeners between conditions. The results for non-native listeners indicated that there were no significant differences in the correct answer rates of any vowels between conditions. Between native and non-native listeners, there was no significant difference in the correct answer rates of each vowel both in the reverberant and non-reverberant condition.

\section{DISCUSSION}

\subsection{Japanese Consonant Identification for Native English Listeners in Reverberation}

The results showed that the correct answer rate for nonnative listeners declined in the reverberant condition more than native listeners against our assumption. As previous studies [6-8] have reported, the results of the current paper also showed that non-native listeners had more difficulty in identifying consonants than native listeners. However, in the current paper, the lower identification rate for nonnative listeners in reverberation was not attributed to the
Table 3 The correct answer rates (\%) of vowels for native listeners in the non-reverberant (non-rev) and reverberant (rev) condition.

\begin{tabular}{rrr}
\hline & non-rev & rev \\
\hline $\mathrm{a}$ & 100.0 & 100.0 \\
$\mathrm{i}$ & 99.2 & 96.1 \\
$\mathrm{u}$ & 100.0 & 100.0 \\
$\mathrm{e}$ & 100.0 & 100.0 \\
$\mathrm{o}$ & 100.0 & 100.0 \\
\hline
\end{tabular}

Table 4 The correct answer rates (\%) of vowels for non-native listeners in the non-reverberant and reverberant condition.

\begin{tabular}{crr}
\hline & non-rev & rev \\
\hline $\mathrm{a}$ & 100.0 & 100.0 \\
$\mathrm{i}$ & 97.9 & 95.8 \\
$\mathrm{u}$ & 99.7 & 98.9 \\
$\mathrm{e}$ & 100.0 & 99.7 \\
$\mathrm{o}$ & 100.0 & 100.0 \\
\hline
\end{tabular}

identification rates of the consonants which did not exist in their native language since the native language of nonnative listeners (i.e., English) has the counterparts to most or all Japanese consonants. The results indicated that the correct answer rates of $/ \mathrm{m}, \mathrm{r} /$ were significantly lower than native listeners. In addition, the rates of $/ \mathrm{k}, \mathrm{d}, \mathrm{s} /$ for nonnative listeners declined in the reverberant condition whereas the rates of the consonants for native listeners did not decline at all in the reverberant condition. The lower identification rate for non-native listeners might be attributed to the rates of $/ \mathrm{m}, \mathrm{r}, \mathrm{k}, \mathrm{d}, \mathrm{s} /$. Since English has counterparts to Japanese /m, r, k, d, s/, the results suggested that non-native listeners might have disadvantage in identifying consonants even if the consonants were in common with their native language.

According to PAM-L2, if non-native listeners hear a phone which is phonetically similar to a phone in their native languages, they perceive the phone as equivalent to a given phonological category of their native languages [9]. Since in the non-reverberant condition, non-native listeners could identify all consonants except $/ \mathrm{n} /$ as well as native listeners, English listeners might not have difficulty in identifying Japanese consonants without reverberation as PAM-L2 claimed. However, in reverberation, non-native listeners had difficulty in identifying consonants which existed in their native language. In the current study, since target CVs were embedded in the carrier sentence, overlapmasking of the phrase preceding the target reduced the intelligibility of the target consonants. The consonants distorted by reverberation might have different characteristics from the typical sounds of the categories (i.e., "good instances," "prototypes") in English, or the characteristics 
Table 5 The inventories of Japanese (top) and English (bottom) consonants.

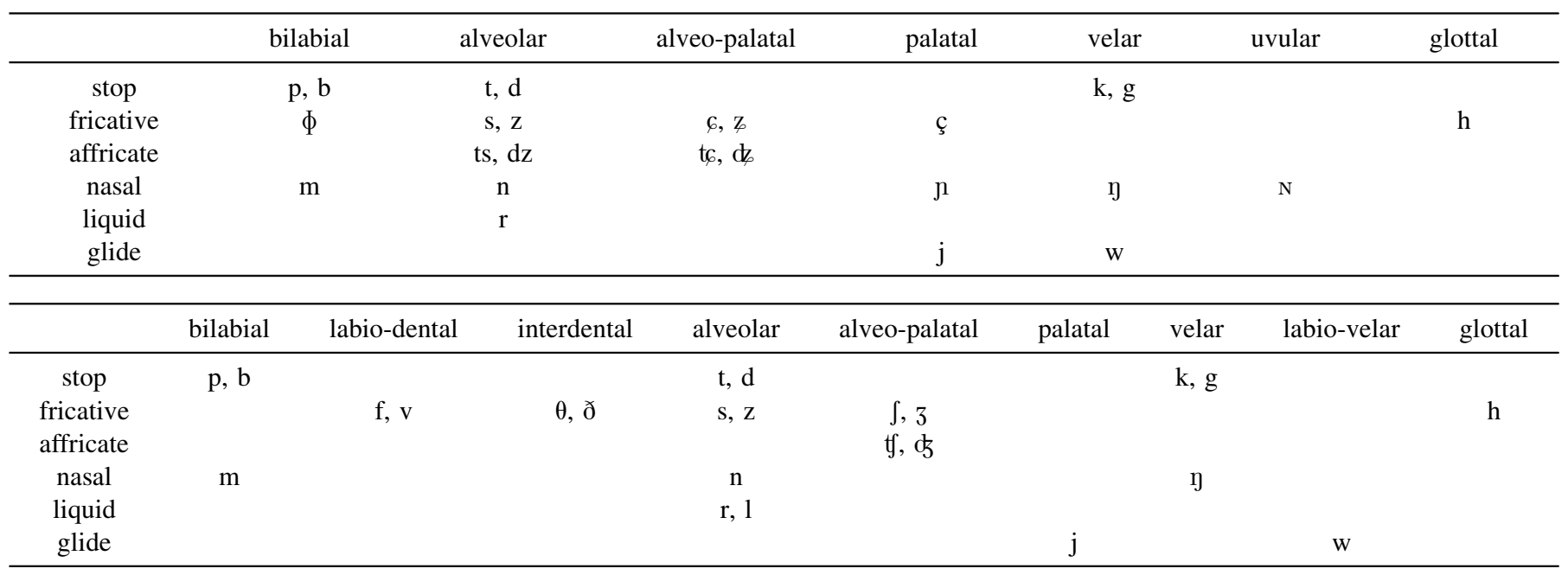

of the prototypes were covered with the tail of the preceding phrase.

In addition, the prototype of a phoneme in a particular language could differ from that of the same phoneme in other languages. For example, Japanese /r/ which is often pronounced as an apico-alveolar tap [13] has different acoustic characteristics from those of English /r/ and /1/. The low identification rate of Japanese / $\mathrm{r}$ / for non-native listeners in reverberation could be attributed to the acoustic difference between Japanese and English.

\subsection{The Difference between Native and Non-native Listeners in the Confusion Patterns}

The results shows that non-native listeners had difficulty in identifying consonants which native listeners also had difficulty in identifying in the reverberant condition. However, there was difference between listener groups in their responses to the stimuli. The results for native listeners showed that the number of place errors was larger than that of manner errors in the reverberant condition whereas the results for non-native listeners showed that the number of manner errors was larger in reverberation.

Generally speaking, the perceptual cues for manner of articulation is more robust than those for place of articulation [16]. In fact, the results for native listeners showed that the number of manner errors was smaller than that of place errors in reverberation. According to Wright [16], constrictions which characterize consonants in terms of manner of articulation is indicated as the attenuation of the signal. Since reverberation distort the temporal structure of speech sounds, the attenuation would be unclear and it would be difficult to find the characteristics of the attenuation which are specific to each manner of articulation. For non-native listeners, it might be difficult to find perceptual cues and identify non-native speech sounds from the attenuation distorted by reverberation. There was the possibility that non-native listeners used different perceptual cues from those native listeners used in reverberation.

In contrast to manner errors, the results showed that there was no significant difference in the number of place errors between native and non-native listeners in reverberation. According to the inventory of consonants in Japanese and English [17] (see Table 5), there are more contrasts based on place of articulation in English. It indicated that English listeners use more perceptual cues for distinguishing consonants than Japanese listeners, and English listeners might be sensitive to the acoustical cues for place of articulation. They might find perceptual cues for place of articulation more easily than they find the cues for manner of articulation.

Previous studies [6-8] discussed the effect of the differences between languages in phoneme systems, and phonemic contrasts specific to each language affected the identification of non-native speech sounds. The results of the current paper suggested that not only phonemic contrasts but also the entire system of phonemes of each language affects the perception in reverberation because their perceptual strategy for distorted sounds might be based on the perceptual sensitivity characterized by native language.

Regarding vowels, the results for non-native listeners showed that there was no significant difference between the reverberant conditions in the correct answer rate of each of all vowels whereas there was significant difference in the correct rate of / $\mathrm{i}$ / for native listeners between conditions. American English has 10 vowels (monophthongs) and British English has 11 vowels (monophthongs) [18] while Japanese has five vowels. Native English listeners might be sensitive to acoustic cue for vowels more than native Japanese listeners. Therefore, they could perceive vowels correctly in reverberation even if the consonants preceding 
a vowel overlapped and reduced the intelligibility in reverberation.

\subsection{The Effect of LOR on Identifying Non-native Consonants}

Comparing to previous studies $[8,19]$, LORs of the nonnative participants of the current study could be regarded as short. The longest LOR in the participants of the current study was 11 months while that of Masuda [8] was 60 months, and that of Flege and Liu [19] was 15.5 years. Shorter LOR is regarded as less experience of listening to non-native speech sounds in the adverse listening environment. Disadvantage discussed in 4.1 and 4.2 could be regarded as characteristics of non-native listeners with short LOR. Further research is required for revealing whether non-native participants with long LOR also have difficulty in identifying non-native consonants in common with their native languages in reverberation.

\section{CONCLUSION}

The current study investigated Japanese CV syllable identification in reverberation for English listeners. We assumed that there would be little difference in the effect of reverberation on the identification of Japanese consonants between listener groups since English had counterparts to most or all Japanese consonants. The results showed that the correct answer rate for non-native listeners declined in the reverberant condition more than native listeners against the assumption. There was the significant difference between native and non-native listeners in the correct answer rate of $/ \mathrm{m}, \mathrm{r}, \mathrm{k}, \mathrm{d}, \mathrm{s} /$ in the reverberation. It indicated that non-native listeners had disadvantage in identifying consonants distorted by reverberation even if their native language had counterparts to the consonants of the target languages.

Analysis of confusion patterns revealed that non-native listeners tended to create errors of manner of articulation whereas the results for native listeners showed that they tended to make place errors in the reverberant condition. Despite robustness of the perceptual cues for manner of articulation, non-native listeners might have disadvantage in finding the perceptual cues for manner of articulation (the attenuation of the signal) from sounds distorted by reverberation. It suggested that non-native listeners needed training for listening speech distorted by reverberation.

Further studies are needed to investigate whether native English listeners who stay in Japan for long time also have difficulty in identifying Japanese consonants since the length of residence in Japan of the participants in the current study was relatively short.

\section{REFERENCES}

[1] T. Arai, E. Osawa, N. Hodoshima and T. Igeta, "Native Japanese speakers' perceptual performance declines in rever- beration,” Proc. Autumn Meet. Acoust. Soc. Jpn., pp. 293-296 (2016).

[2] T. Arai, E. Osawa, N. Hodoshima and T. Igeta, "Reverberation degrades native listeners' perception of Japanese monosyllables/special morae," Acoust. Sci. \& Tech., 39, 252-255 (2018).

[3] E. Osawa, T. Arai, N. Hodoshima and T. Igeta, "Non-native speakers perform poorer than native speakers in Japanese speech recognition in reverberation," J. Acoust. Soc. Am., 140, 3333 (2016).

[4] R. H. Bolt and A. D. MacDonald, "Theory of speech masking by reverberation," J. Acoust. Soc. Am., 21, 577-580 (1949).

[5] A. K. Nábělek, T. R. Letowski and F. M. Tucker, "Reverberant overlap- and self-masking in consonant identification," $J$. Acoust. Soc. Am., 86, 1259-1265 (1989).

[6] A. K. Nábělek and A. M. Donahue, "Perception of consonants in reverberation by native and non-native listeners," J. Acoust. Soc. Am., 75, 632-634 (1984).

[7] Y. Takata and A. K. Nábělek, "English consonant recognition in noise and in reverberation by Japanese and American listeners," J. Acoust. Soc. Am., 88, 663-666 (1990).

[8] H. Masuda, "Misperception patterns of American English consonants by Japanese listeners in reverberant and noisy environments," Speech Commun., 79, 74-87 (2016).

[9] C. T. Best and M. D. Tyler, "Nonnative and second-language speech perception: Commonalities and complementarities," in Language Experience in Second Language Speech Learning: In Honor of James Emil Flege, pp. 13-34 (2007).

[10] P. K. Kuhl and P. Iverson, "Linguistic experience and the "perceptual magnet effect"," in Speech Perception and Linguistic Experience: Issues in Cross-language Research, pp. 121-154 (1995).

[11] J. E. Flege, "Second language speech learning: Theory, findings, and problems," Speech Perception and Linguistic Experience: Issues in Cross-language Research, pp. 233-277 (1995).

[12] N. Hodoshima, T. Arai, A. Kusumoto and K. Kinoshita, "Improving syllable identification by a preprocessing method reducing overlap-masking in reverberant environments," $J$. Acoust. Soc. Am., 119, 4055-4064 (2006).

[13] T. J. Vance, The Sound of Japanese (Cambridge University Press, New York, 2008).

[14] S. Yokoyama, H. Mukai and H. Tachibana, "Examples of field measurement of acoustic conditions in public spaces," J. Inst. Noise Control Eng. Jpn., 23, 228-231 (1999).

[15] P. Boersma and D. Weenink, "Praat, a system for doing phonetics by computer," Glot Int., 5(9/10), 341-345 (2001).

[16] R. Wright, "A review of perceptual cues and cue robustness," in Phonetically Based Phonology, pp. 34-57 (2004).

[17] N. Tsujimura, An Introduction to Japanese Linguistics (John Wiley \& Sons, Chichester, 2014).

[18] P. Ladefoged and K. Johnson, A Course in Phonetics, 6th ed. (Wadsworth Cengage Learning, Boston, 2011).

[19] J. E. Flege and S. Liu, "The effect of experience on adults' acquisition of a second language," Stud. Second Lang. Acqu., 23, 527-552 (2001).

\section{APPENDIX}

Appendices 1-4 give confusion matrices of consonants. Appendices 1 and 2 show the results for native listeners in the non-reverberant and reverberant condition. Appendices 3 and 4 show the results for non-native listeners in the nonreverberant condition and reverberant condition. 
E. OSAWA et al.: PERCEPTION IN REVERBERATION BY NON-NATIVES

Appendix 1 The correct answer rates (\%) for native listeners in the non-reverberant condition.

\begin{tabular}{|c|c|c|c|c|c|c|c|c|c|c|c|c|c|c|c|c|c|c|}
\hline & \multicolumn{18}{|c|}{ Response } \\
\hline Stimuli & $\mathrm{p}$ & $\mathrm{b}$ & $\mathrm{t}$ & $\mathrm{d}$ & $\mathrm{k}$ & g & $\mathrm{s}$ & 6 & $\mathrm{dz}$ & d & $\mathrm{h}$ & to & ts & $\mathrm{m}$ & $\mathrm{n}$ & $\mathrm{r}$ & $\mathrm{j}$ & $\mathrm{w}$ \\
\hline $\mathrm{p}$ & 95.8 & & 4.2 & & & & & & & & & & & & & & & \\
\hline $\mathrm{b}$ & & 93.3 & & 4.8 & & & 0.6 & & & & & & & & & 1.2 & & \\
\hline $\mathrm{t}$ & & & 100.0 & & & & & & & & & & & & & & & \\
\hline $\mathrm{d}$ & & & & 100.0 & & & & & & & & & & & & & & \\
\hline $\mathrm{k}$ & & & & & 99.4 & & & & & & & 0.6 & & & & & & \\
\hline g & & & & & & 100.0 & & & & & & & & & & & & \\
\hline $\mathrm{s}$ & & & & & & & 100.0 & & & & & & & & & & & \\
\hline 6 & & & & & & & 6.1 & 93.9 & & & & & & & & & & \\
\hline $\mathrm{dz}$ & & & & & & 0.8 & & & 99.2 & & & & & & & & & \\
\hline do & & & & & & 15.2 & & & & 84.8 & & & & & & & & \\
\hline $\mathrm{h}$ & & & & & & & & & & & 100.0 & & & & & & & \\
\hline th & & & & & & & & & & & & 100.0 & & & & & & \\
\hline ts & & & & & & & & & & & & & 100.0 & & & & & \\
\hline $\mathrm{m}$ & & & & & & & & & & & & & & 98.2 & 1.8 & & & \\
\hline $\mathrm{n}$ & & & & & & & & & & & & & & & 94.5 & 5.5 & & \\
\hline $\mathrm{r}$ & & & & & & & & & & & & & & & & 100.0 & & \\
\hline $\mathrm{j}$ & & & & & & & & & & & & & & & & 2.0 & 98.0 & \\
\hline w & & & & & & & & & & & & & & & & & & 100.0 \\
\hline
\end{tabular}

Appendix 2 The correct answer rates (\%) for native listeners in the reverberant condition.

\begin{tabular}{|c|c|c|c|c|c|c|c|c|c|c|c|c|c|c|c|c|c|c|}
\hline & \multicolumn{18}{|c|}{ Response } \\
\hline Stimuli & $\mathrm{p}$ & $\mathrm{b}$ & $\mathrm{t}$ & d & $\mathrm{k}$ & $\mathrm{g}$ & $\mathrm{s}$ & 6 & $\mathrm{dz}$ & do & $\mathrm{h}$ & t6 & ts & $\mathrm{m}$ & $\mathrm{n}$ & $\mathrm{r}$ & $\mathrm{j}$ & $\mathrm{w}$ \\
\hline $\mathrm{p}$ & 73.3 & & 8.5 & & 6.1 & & & & & & 12.1 & & & & & & & \\
\hline $\mathrm{b}$ & 5.5 & 80.6 & & 6.7 & & 6.1 & & & & & & & & & & 1.2 & & \\
\hline $\mathrm{t}$ & 12.1 & & 59.6 & & 28.3 & & & & & & & & & & & & & \\
\hline $\mathrm{d}$ & & & & 100.0 & & & & & & & & & & & & & & \\
\hline $\mathrm{k}$ & & & & & 99.4 & & & & & & 0.6 & & & & & & & \\
\hline $\mathrm{g}$ & & 0.6 & & & 9.1 & 89.1 & & & & & 1.2 & & & & & & & \\
\hline $\mathrm{s}$ & & & & & & & 100.0 & & & & & & & & & & & \\
\hline 6 & & & & & & & 27.3 & 69.7 & & & & & & & 3.0 & & & \\
\hline $\mathrm{dz}$ & & & & & & & & & 97.7 & & & & 2.3 & & & & & \\
\hline d & & & & & & & & & & 36.4 & & 63.6 & & & & & & \\
\hline $\mathrm{h}$ & 7.3 & & 1.2 & & 1.8 & & & & & & 89.7 & & & & & & & \\
\hline t6 & & & & & & & & & & & & 100.0 & & & & & & \\
\hline ts & & & & & & & & & & & & & 100.0 & & & & & \\
\hline $\mathrm{m}$ & 0.6 & 15.2 & & & 0.6 & 1.2 & & & & & 0.6 & & & 81.2 & & 0.6 & & \\
\hline $\mathrm{n}$ & & 4.2 & & 4.8 & & 0.6 & & & & & 0.6 & & & 24.2 & 44.8 & 20.6 & & \\
\hline $\mathrm{r}$ & & 6.1 & & 1.2 & & 0.6 & & & & & & & & & & 92.1 & & \\
\hline $\mathrm{j}$ & & & & & & & & & & & & & & & & & 100.0 & \\
\hline w & & & & & & & & & & & 3.0 & & & & & & & 97.0 \\
\hline
\end{tabular}


Acoust. Sci. \& Tech. 39, 6 (2018)

Appendix 3 The correct answer rates (\%) for non-native listeners in the non-reverberant condition.

\begin{tabular}{|c|c|c|c|c|c|c|c|c|c|c|c|c|c|c|c|c|c|c|}
\hline & \multicolumn{18}{|c|}{ Response } \\
\hline Stimuli & $\mathrm{p}$ & $\mathrm{b}$ & $\mathrm{t}$ & d & $\mathrm{k}$ & $\mathrm{g}$ & $\mathrm{s}$ & 6 & $\mathrm{dz}$ & d & $\mathrm{h}$ & t6 & ts & $\mathrm{m}$ & $\mathrm{n}$ & $\mathrm{r}$ & $\mathrm{j}$ & w \\
\hline $\mathrm{p}$ & 98.7 & & 1.3 & & & & & & & & & & & & & & & \\
\hline $\mathrm{b}$ & & 93.3 & & 4.7 & & 1.3 & & & & & & & & & & 0.7 & & \\
\hline $\mathrm{t}$ & & & 100.0 & & & & & & & & & & & & & & & \\
\hline $\mathrm{d}$ & & & 1.1 & 96.7 & & & & & & & & & & & & 2.2 & & \\
\hline $\mathrm{k}$ & & & & & 95.3 & & & & & 0.7 & & 4.0 & & & & & & \\
\hline $\mathrm{g}$ & & & & & & 100.0 & & & & & & & & & & & & \\
\hline $\mathrm{s}$ & & & & & & & 94.2 & & & & & & 5.8 & & & & & \\
\hline 6 & & & & & & & & 90.0 & 3.3 & & & & 6.7 & & & & & \\
\hline $\mathrm{dz}$ & & & & & & & & & 98.3 & & & & 1.7 & & & & & \\
\hline do & & & & & & 13.3 & & & & 86.7 & & & & & & & & \\
\hline $\mathrm{h}$ & & & & & & & & & & & 100.0 & & & & & & & \\
\hline th & & & & & & & & & & & & 100.0 & & & & & & \\
\hline ts & & & & & & & 3.3 & & & & & & 96.7 & & & & & \\
\hline $\mathrm{m}$ & & & & & & & & & & & & & & 98.7 & 1.3 & & & \\
\hline $\mathrm{n}$ & & & & & & & & & & & & & & 4.0 & 78.0 & 18.0 & & \\
\hline $\mathrm{r}$ & & & & & & & & & & & & & & & & 100.0 & & \\
\hline $\mathrm{j}$ & & & & & & & & & & & & & & & & & 100.0 & \\
\hline $\mathrm{w}$ & & & & & & & & & & & & & & & & & & 100.0 \\
\hline
\end{tabular}

Appendix 4 The correct answer rates (\%) for non-native listeners in the reverberant condition.

\begin{tabular}{|c|c|c|c|c|c|c|c|c|c|c|c|c|c|c|c|c|c|c|}
\hline & & & & & & & & & Resp & onse & & & & & & & & \\
\hline Stimuli & $\mathrm{p}$ & b & $\mathrm{t}$ & $\mathrm{d}$ & $\mathrm{k}$ & $\mathrm{g}$ & $\mathrm{s}$ & 6 & $\mathrm{dz}$ & d & $\mathrm{h}$ & $t_{6}$ & ts & $\mathrm{m}$ & $\mathrm{n}$ & $\mathrm{r}$ & $\mathrm{j}$ & w \\
\hline $\mathrm{p}$ & 81.3 & & 2.0 & & 2.7 & 1.3 & & & & & 12.7 & & & & & & & \\
\hline b & 8.7 & 74.0 & & 6.7 & & 4.0 & & & 0.7 & & 2.0 & & & 0.7 & 0.7 & 2.7 & & \\
\hline $\mathrm{t}$ & 15.6 & & 61.1 & & 21.1 & & & & & & 2.2 & & & & & & & \\
\hline $\mathrm{d}$ & & & 1.1 & 84.4 & & 1.1 & 1.1 & & & & & & & & & 12.2 & & \\
\hline $\mathrm{k}$ & 5.3 & & & & 92.7 & 0.7 & & & 0.7 & & & 0.7 & & & & & & \\
\hline $\mathrm{g}$ & 0.7 & 4.7 & & & 2.7 & 87.3 & & & & & 4.0 & & & & & 0.7 & & \\
\hline $\mathrm{s}$ & & & 0.8 & & & & 86.7 & & 5.0 & & & & 7.5 & & & & & \\
\hline 6 & & & & & & & 13.3 & 70.0 & & & & 3.3 & 13.3 & & & & & \\
\hline $\mathrm{dz}$ & & & & & & & 0.8 & & 94.2 & & & & 5.0 & & & & & \\
\hline d & & & & & & 3.3 & & & & 23.3 & & 73.3 & & & & & & \\
\hline $\mathrm{h}$ & 6.7 & & & 0.7 & 0.7 & & & & & & 92.0 & & & & & & & \\
\hline t6 & & & & & & & & & & 6.7 & & 93.3 & & & & & & \\
\hline ts & & & & & & & 10.0 & & & & & & 86.7 & 3.3 & & & & \\
\hline $\mathrm{m}$ & 2.0 & 26.7 & & & & 0.7 & & & & & 5.3 & & & 58.7 & 1.3 & 5.3 & & \\
\hline $\mathrm{n}$ & 0.7 & 10.0 & & 2.0 & & 0.7 & & & & & 0.7 & & & 19.3 & 22.7 & 42.7 & 1.3 & \\
\hline $\mathrm{r}$ & 1.3 & 12.0 & & 0.7 & & 2.7 & & & & & & & & 0.7 & & 81.3 & 1.3 & \\
\hline $\mathrm{j}$ & & & & & & & & & & & & & & & & 2.2 & 97.8 & \\
\hline w & & 6.7 & & & & & & & & & & & & & & & & 93.3 \\
\hline
\end{tabular}

